\title{
BROKEN HEART AS WORK-RELATED ACCIDENT: OCCUPATIONAL STRESS AS A CAUSE OF TAKOTSUBO CARDIOMYOPATHY IN 55-YEAR-OLD FEMALE TEACHER - ROLE OF AUTOMATED FUNCTION IMAGING IN DIAGNOSTIC WORKFLOW
}

\author{
AGNIESZKA MIELCZAREK ${ }^{1}$, JAROSŁAW DAMIAN KASPRZAK ${ }^{1}$, ANDRZEJ MARCINKIEWICZ ${ }^{2}$, \\ MAŁGORZATA KURPESA ${ }^{1}$, BARBARA UZNAŃSKA-LOCH ${ }^{1}$, and KARINA WIERZBOWSKA-DRABIK ${ }^{1}$ \\ ${ }^{1}$ Medical University of Lodz, Łódź, Poland \\ Chair and Department of Cardiology \\ ${ }^{2}$ Nofer Institute of Occupational Medicine, Łódź, Poland \\ Department of Environmental Epidemiology
}

\begin{abstract}
Takotsubo cardiomiopathy (TTC) (known also as "ampulla cardiomyopathy," "apical ballooning" or "broken heart syndrome") is connected with a temporary systolic left ventricular dysfunction without the culprit coronary lesion. Takotsubo cardiomyopathy was first described in 1990 in Japan after octopus trapping pot with a round bottom and narrow neck similar in shape to left ventriculogram in TTC patients. The occurrence of TTC is usually precipitated by a stressful event with a clinical presentation mimicking myocardial infarction: chest pain, ST-T segment elevation or T-wave inversion, a rise in cardiac troponin, and contractility abnormalities in echocardiography. A left ventricular dysfunction is transient and improves within a few weeks. Takotsubo cardiomyopathy typically occurs in postmenopausal women and the postulated mechanism is catecholamine overstimulation. Moreover, the distribution of contractility impairments usually does not correspond with typical region supplied by a single coronary artery. Therefore, the assessment of regional pattern of systolic dysfunction with speckle-tracking echocardiography and automated function imaging (AFI) technique may be important in diagnosis of TTC and may improve our insight into its patophysiology. We described a 55-year-old female teacher with TTC diagnosed after acute psychological stress in workplace. The provoking factor related with occupational stress and pattern of contraction abnormalities documented with AFI technique including basal segments of left ventricle make this case atypical.
\end{abstract}

Key words:

Occupational stress, Takotsubo cardiomyopathy, Broken heart syndrome, Accident at work, Automated function imaging, Speckle tracking echocardiography

Received: January 9, 2015. Accepted: May 9, 2015.

Corresponding author: K. Wierzbowska-Drabik, Medical University of Lodz, Department of Cardiology, Kniaziewicza 1/5, 91-347 Łódź, Poland (e-mail: wierzbowska@ptkardio.pl). 


\section{INTRODUCTION}

Under Polish law, an accident at work is a sudden event caused by an external factor leading to health damage or death and resulting from duties performed at work [1]. Occupational stress is a recognized cause of cardiovascular acute events, which can be classified as an accident at work. Myocardial infarctions are the most frequent of these cardiological problems [2]. Nevertheless, there is little information regarding the connection between stress at work and transient acute heart syndrome called takotsubo cardiomyopathy (TTC) $[3,4]$.

\section{CASE REPORT}

We report a case of a 55-year-old woman, a teacher in high school, admitted to an intensive cardiac unit for acute chest pain and dyspnea lasting about $6 \mathrm{~h}$. The occupational stress was recognized as a triggering factor, because the symptoms occurred after severe quarrel with her boss during teachers council session. Dyslipidemia and hypertension were detected from the cardiovascular risk factors.

On examination, electrocardiogram revealed sinus tachycardia 92/min and $1 \mathrm{~mm}$ ST-segment depression in leads V4-V6 and T-wave inversion in aVL. Laboratory findings obtained at admission included elevated biomarkers of myocardial necrosis: troponin T $0.295 \mu \mathrm{g} / \mathrm{l}$ and the combination of isoenzymes $\mathrm{M}$ and $\mathrm{B}$ of creatine kinase (CK-MB) $5.95 \mu \mathrm{g} / \mathrm{l}$. The levels of C-reactive protein (CRP) was $6.62 \mathrm{mg} / \mathrm{l}$; triglicerides $278 \mathrm{mg} / \mathrm{dl}$ and $\mathrm{N}$-terminal of the prohormone brain natriuretic peptide (NT-proBNP) $1990 \mathrm{pg} / \mathrm{ml}$ were also increased.

The transthoracic echocardiography displayed visually assessed akinesis of middle left ventricular segments presenting even as dyskinesis of mid septal, anterior and inferior wall segments, hyperkinetic function of basal and apical segments and mildly decreased global ejection fraction of $46 \%$ in 3D echocardiography (Photo 1a and $1 \mathrm{~b})$. Assessed with pulsed tissue Doppler mitral annulus motion measured in septal part of annulus revealed decreased velocity of $6 \mathrm{~cm} / \mathrm{s}$ (Photo $1 \mathrm{~d}$ ).

The ratio of the early (E) to late (A) ventricular filling velocities (E/A ratio) of mitral inflow was $0.8 \mathrm{~cm} / \mathrm{s}$ and propagation velocity of early mitral wave was lowered to $33 \mathrm{~cm} / \mathrm{s}$; all these parameters corresponded with diastolic dysfunction in delayed relaxation stage. Automated function imaging (AFI) analysis provided polar map (bull-eye) of left ventricle revealing severely impaired peak systolic longitudinal strain (PSLS) (absolute value of PSLS $<10 \%$ ) in 3 segments and moderately impaired PSLS (absolute value of PSLS $<15 \%$ ) in another 5 segments (Photo 1c).

Coronary angiography revealed completely normal coronary arteries, without the need of invasive intervention; instead, pharmacotherapy consisting of acetylsalicylic acid, betaadrenolytic, angiotensin-converting-enzyme inhibitor (ACE-inhibitor) and statin was initiated. During hospitalization the patient was stable, without recurrences of angina.

Follow-up echocardiography examination performed 3 days later revealed significant improvement of contractility with sustained mild hypokinesis of mid anterior and inferior segments and left ventricular ejection fraction $57 \%$ (Photo 1e). Also diastolic function improved, as evidenced by early diastolic velocity of mitral annulus increased to $10 \mathrm{~cm} / \mathrm{s}$ (Photo $1 \mathrm{~g}$ ). Absolute value of peak systolic longitudinal strain increased in formerly abnormal basal anterior and anteroseptal segments, revealing still values $<15 \%$ (Photo 1f). In laboratory tests, biomarkes of myocardial necrosis gradually normalized.

After analysis of all data, a diagnosis of TTC based on Mayo Clinic Criteria was established. Transient akinesis of mid left ventricular segments, the presence of stressful trigger, the absence of coronary artery lesion simultaneously with modest elevation in cardiac troponin and new electrocardiographic abnormalities are typical for this 


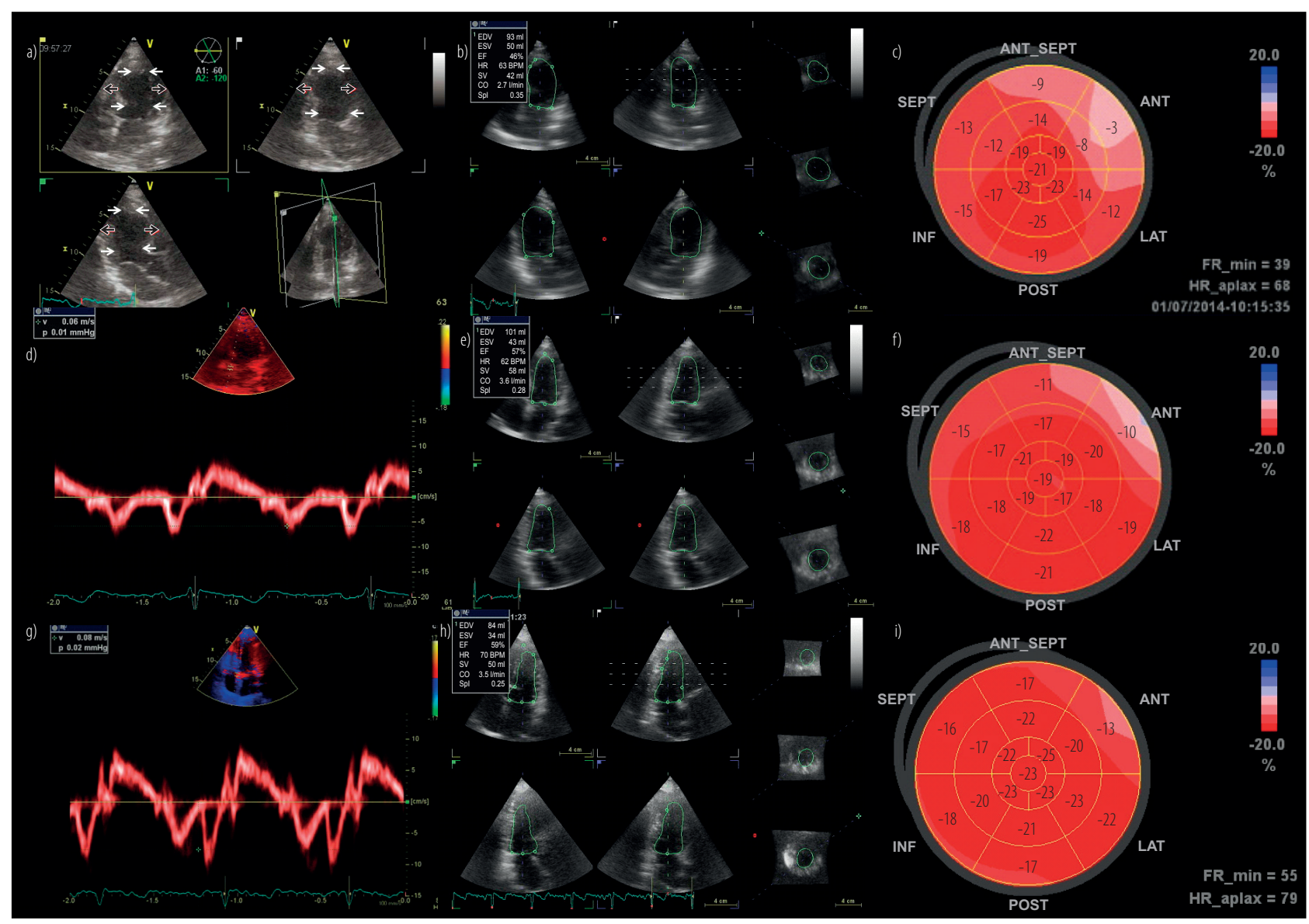

a) Systolic frame of apical views recorded by 3D echocardiography showing bulging of akinetic mid-ventricular segments. White arrows indicate normal inward motion of endocardium in apical and basal parts of left ventricle. Black with white contour arrows indicate abnormal outward motion of endocardium in mid akinetic or dyskinetic segments.

b) Mildly impaired ejection fraction $46 \%$ during acute phase of TTC.

c) Polar map of left ventricle during acute phase of TTC showing decreased absolute values of peak systolic longitudinal strain $(<15 \%)$ in 8 segments.

d) Mitral annulus motion showing decreased early diastolic velocity during acute phase of TTC, E' in septal part of mitral annulus $6 \mathrm{~cm} / \mathrm{s}$.

e) Improved left ventricular ejection fraction after 3 days, ejection fraction (EF) $57 \%$.

f) Polar map of left ventricle 3 days after onset of TTC. Peak systolic longitudinal strain less than $15 \%$ in 2 segments: basal anterior and basal anteroseptal.

g) Normalized motion of mitral annulus during follow-up examination, E’ in septal part of mitral annulus $8 \mathrm{~cm} / \mathrm{s}$.

h) Normal left ventricular ejection fraction 59\% calculated by 3D echocardiography after 3 weeks follow-up.

i) Polar map of left ventricle 3 weeks after onset of TTC showing slightly impaired longitudinal strain only in basal anterior segment.

Photo 1. Evolution of takotsubo cardiomyopathy (TTC) assessed by 3D, tissue Doppler echocardiography and polar maps generated by automated function imaging

syndrome [5-7]. Also female sex and postmenopausal age are usual in TTC. Less typical was the trigger connected with professional activity and, rarely observed so far, dysfunction of basal segments documented by AFI method as lowered longitudinal strain. The patient was advised to avoid stress situations and to undergo transthoracic examination after 3 weeks for monitoring left ventricular function. 
The follow-up echocardiographic examination showed normokinetic myocardium with ejection fraction $59 \%$ and normalized regional strain parameters, apart from mildly lowered peak systolic strain in basal segment of anterior wall (Photo $1 \mathrm{~h}$ and 1i). The observed improvement confirmed a diagnosis of TTC and allowed to reassure the patient about favourable prognosis. Interestingly, impaired longitudinal strain, especially in the acute phase, was observed not only in mid-ventricular part of left ventricle but also in basal segments, despite the visual perception of basal hypercontractility. Our observations in this point are however concordant with those reported by Heggemann et al., who documented acute decrease of longitudinal strain in the basal anterior and anteroseptal segments in patients with classical form of TTC [8].

\section{CONCLUSIONS}

The diagnosis of TTC should be considered in patients with chest pain related to physical or emotional stress. Our case focuses on rarely reported situation of TTC where occupational stress was playing a vital role. The case meets the criteria for an accident at work - the stress resulting from a quarrel with the headmaster was an external cause leading to health damage (recognized as a takotsubo syndrome), which occurred at a workplace (during the staff meeting of the school). The quantitative assessment of deformation by AFI method supported reversible character of systolic dysfunction and indicated that segmental pattern of impaired longitudinal strain may not fully correspond with visually observed regional systolic dysfunction.

\section{REFERENCES}

1. [The Act of 30 October 2002 on the national insurance on account of accidents at work and occupational diseases. J Laws 2009, No. 167, item 1322 (Nov 28, 2009)]. Polish

2. WiśniewskiS, Kordel K, Olasińska-Wiśniewska A, WiśniewskaŚliwińska H, Marcinkowski J. [Stress factor and its importance in the development of cardiac vascular acute cases - Expertise problems]. Orzecznictwo Lek. 2010;7(2):113-9. Polish.

3. Backe E, Seidler A, Latza U. The role of psychosocial stress at work for the development of cardiovascular diseases: A systematic review. Int Arch Occup Environ Health. 2012;85:6779, http://dx.doi.org/10.1007/s00420-011-0643-6.

4. Salska A, Chiżyński K, Salski W, Wiszniewska M, WalusiakSkorupa J. [Rare cardiovascular diseases in the context of occupational health care]. Med Pr. 2014;65(6):847-56, http:// dx.doi.org/10.13075/mp.5893.00003. Polish.

5. Scantlebury DC, Prasad A. Diagnosis of takotsubo cardiomyopathy. Mayo Clinic criteria. Circ J. 2014;78:2129-39, http:// dx.doi.org/10.1253/circj.CJ-14-0859.

6. Uznańska B, Plewka M, Wierzbowska-Drabik K, Chrzanows$\mathrm{ki} \ell$, Kasprzak JD. Early prediction of ventricular recovery in Takotsubo syndrome using stress and contrast echocardiography. Med Sci Monit. 2009;15(6):CS89-94.

7. Prasad A, Lerman A, Rihal CS. Apical ballooning syndrome (tako-tsubo or stress cardiomyopathy): A mimic of acute myocardial infarction. Am Heart J. 2008;155:408-17, http:// dx.doi.org/10.1016/j.ahj.2007.11.008.

8. Heggemann F, Weiss C, Hamm K, Kaden J, Süselbeck T, Papavassiliu T, et al. Global and regional myocardial function quantification by two-dimensional strain in Takotsubo cardiomyopathy. Eur J Echocardiogr. 2009;10:760-4, http://dx.doi. org/10.1093/ejechocard/jep062.

This work is available in Open Access model and licensed under a Creative Commons Attribution-NonCommercial 3.0 Poland License - http://creativecommons.org/ licenses/by-nc/3.0/pl/deed.en. 